\title{
Off-label use of recombinant factor VIla: why we need better drug monitoring
}

\author{
Paul C. Hébert MD MHSc, Dean Fergusson MHA PhD, Matthew B. Stanbrook MD PhD
}

See related research article by Lin and colleagues at www.cmaj.ca, and related synopsis, page E9

Competing interests: See www.cmaj.ca/misc/cmaj_ staff.dtl (Hébert, Stanbrook). Paul Hébert and Dean Fergusson were paid by Novo Nordisk to sit on independent data monitoring and safety committees.

This commentary has not been peer reviewed.

Correspondence to: Dr. Paul C. Hébert, paul.hebert@cmaj.ca

CMAJ 2011. DOI:10.1503 /cmaj.101842
$\mathrm{T}$ wo recent reviews describe outcomes associated with the very expensive offlabel use of recombinant factor VIIa for the treatment or prevention of massive bleeding. One of the reviews points to marginal improvements in terms of survival and rates of transfusion; ${ }^{1}$ the other documents a $2.3 \%$ absolute (68\% relative) risk of arterial thromboembolic events. ${ }^{2}$ Sadly, this evidence of recombinant factor VIIa's limited benefits and serious safety concerns comes long after adoption of the off-label use of the drug into clinical practice to prevent or treat massive bleeding from cardiac surgery, trauma or other causes.

Recombinant factor VIIa was first licensed in 1996 to treat or prevent bleeding connected with surgery in people with hemophilia who have inhibitors to factor VIII. ${ }^{3}$ Shortly thereafter, a case report described its role in the "miraculous cessation of bleeding" in a wounded soldier. This was followed by more case reports in different surgical disciplines. Many key physician opinion leaders touted its off-label use to treat or prevent bleeding in patients without hemophilia, which set off a windfall in sales for the manufacturer. According to data from a hemostasis registry in Australia and New Zealand (one of the few available sources of such data), patients without hemophilia accounted for an estimated $99 \%$ of the product's use.

The rapid uptake of this expensive recombinant protein in patients for whom safety and outcome information was lacking shows serious shortcomings in the current drug surveillance system. Off-label use was not driven by company advertising (which would have been illegal) but, rather, by physicians themselves in the

\section{- KeY POINTS}

- Off-label use of medications is potentially unsafe.

- Use of recombinant factor VIla to prevent or treat bleeding in patients without hemophilia is very expensive, marginally effective and risky.

- Priority should be placed on several key monitoring and regulatory strategies that will better protect patients. hopes of helping patients at immediate risk of death. Recombinant factor VIIa is but one example in which promising case reports have driven practice prematurely.

Monitoring of reasons for the use of recombinant factor VIIa was limited in most jurisdictions. Regulatory authorities have few monitoring and enforcement tools at their disposal, and more often than not, they do not want to be seen as interfering with therapeutic choices made by health care professionals. Canadian Blood Services, the product supplier for most of Canada, watched use and costs rise but was unable to curb practice with guidelines and knowledgetranslation approaches. Because recombinant factor VIIa is a blood product, hospital pharmacy and therapeutic committees are not generally called upon to review and monitor usage and outcomes. Héma-Québec was better able to ensure appropriate standard usage through an access policy, through which a medical expert was available for immediate consultation to advise on all therapeutic modalities for massive bleeding. The system for reporting adverse events was passive. Fourteen years elapsed from the first reported case ${ }^{4}$ to the publication of a review funded by the manufacturer. ${ }^{2}$

This saga illustrates how serious adverse effects in complicated patients may be detected only after several trials using similar products are considered together. Artificial oxygen carriers represent another recent example. In a meta-analysis of randomized trials of artificial oxygen carriers, Natanson and colleagues found that the risk of death and myocardial infarction was significantly increased with the use of these new compounds. ${ }^{6}$

Off-label use of drugs can be beneficial. However, without a process for ongoing evaluation, deaths, disabilities and costs may be accruing without being obvious at the bedside. With recombinant factor VIIa, physicians were too eager to believe the anecdotes and did not push for appropriate studies. Interestingly, although many physicians in the developed world were focused on a high-cost, data-poor novel therapy,

All editorial matter in CMAJ represents the opinions of the authors and not necessarily those of the Canadian Medical Association. 
others were finding benefits with a cheaper, older therapy. A study involving 20211 patients following multiple trauma in 40 countries, mostly in the developing world, showed that tranexamic acid, a much less expensive treatment than recombinant factor VIIa, decreased mortality by $1.5 \%$ compared with placebo.?

Monitoring drug use as well as safety is a complex problem without a simple solution, but many possible changes bear consideration. ${ }^{8} \mathrm{Col}-$ laboration could be improved between payers and insurers who approve and track usage, and manufacturers. Health care professionals could be more willing to push for, and participate in, evidence-based evaluations of new drugs. An improved drug surveillance system might prioritize independent, prospective and timely surveillance of uses and adverse events of higher risk drugs. Population-based retrospective evaluations could be organized for all new drugs by jurisdictions such as Canada that have an existing infrastructure to facilitate this research. Collaborative efforts among regulatory authorities could minimize duplication of similar evaluations and maximize the total number of drugs evaluated. Other, more reliable mechanisms for reporting adverse events could be created to replace Canada's current voluntary system. Incentives such as extension of patents could be offered to manufacturers to ensure that appropriate trials are undertaken early and that all results of completed trials are made available in a timely manner. Simultaneously, regulatory authorities could be given greater powers to enforce postmarketing surveillance.
The consequences of inaction are real. With all stakeholders working together, reasonable steps can be taken to improve the monitoring of drug effectiveness and safety.

\section{References}

1. Lin Y, Stanworth S, Birchall J, et al. Use of recombinant factor VIIa for the prevention and treatment of bleeding in patients without hemophilia: a systematic review and meta-analysis. CMAJ 2011:183;E9-19.

2. Levi M, Levy JH, Andersen HF, et al. Safety of recombinant activated factor VII in randomized clinical trials. $N$ Engl J Med 2010;363:1791-800.

3. European Medicines Agency. NovoSeven. London (UK): The Agency; 2010. Available: www.ema.europa.eu/ema/index.jsp ?curl=pages/medicines/human/medicines/000074/human_med _000936.jsp\&murl=menus/medicines/medicines.jsp\&mid=WC 0b01ac058001d125 (accessed 2010 Dec. 10).

4. Kenet G, Walden R, Eldad A, et al. Treatment of traumatic bleeding with recombinant factor VIIa. Lancet 1999;354:1879.

5. The Haemostasis Registry - How far have we come and what do we have to show for it? Victoria (Australia): Monash University; 2008. Available: www.med.monash.edu.au/epidemiology /traumaepi/workshop09.html (accessed 2010 Dec. 10).

6. Natanson C, Kern SJ, Lurie P, et al. Cell-free hemoglobin-based blood substitutes and risk of myocardial infarction and death: a meta-analysis. JAMA 2008;299:2304-12.

7. CRASH-2 Trial Collaborators; Shakur H, Roberts I, Bautista R, et al. Effects of tranexamic acid on death, vascular occlusive events, and blood transfusion in trauma patients with significant haemorrhage (CRASH-2): a randomised, placebo-controlled trial. Lancet 2010;376:23-32.

8. Hébert PC, Stanbrook M. Indication creep: physician beware. CMAJ 2007; 177:697, 699.

Affiliations: Paul Hébert is Editor-in-Chief and Matthew Stanbrook is Deputy Editor, Scientific, of CMAJ. Dean Fergusson is Senior Scientist and Director, Clinical Epidemiology Program, Ottawa Hospital Research Institute, and Associate Professor, Departments of Medicine and of Epidemiology and Community Medicine, University of Ottawa, Ottawa, Ont.

Contributors: All of the authors contributed substantially to the writing and revising of the manuscript and approved the final version submitted for publication.

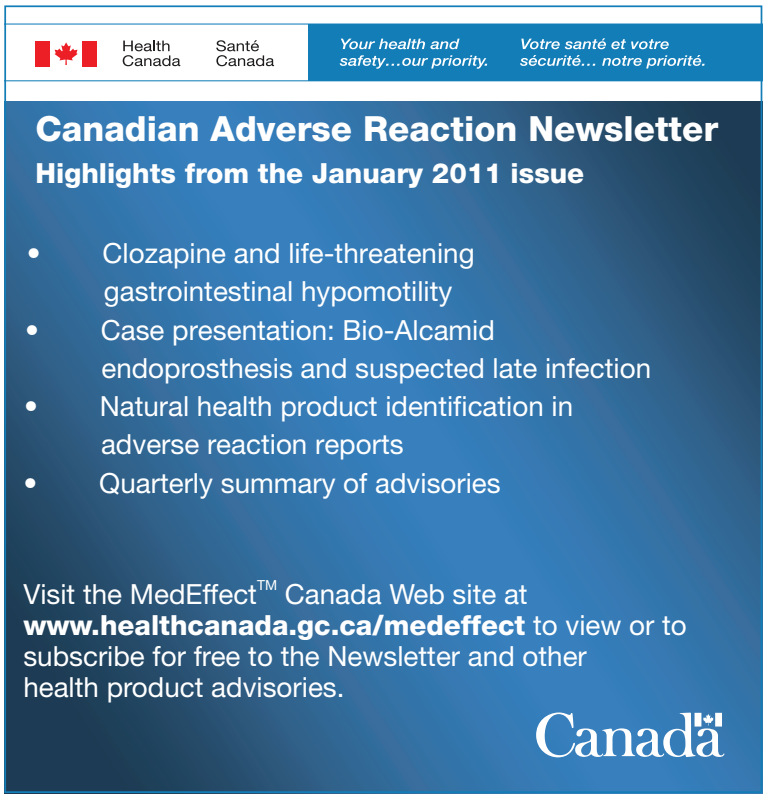

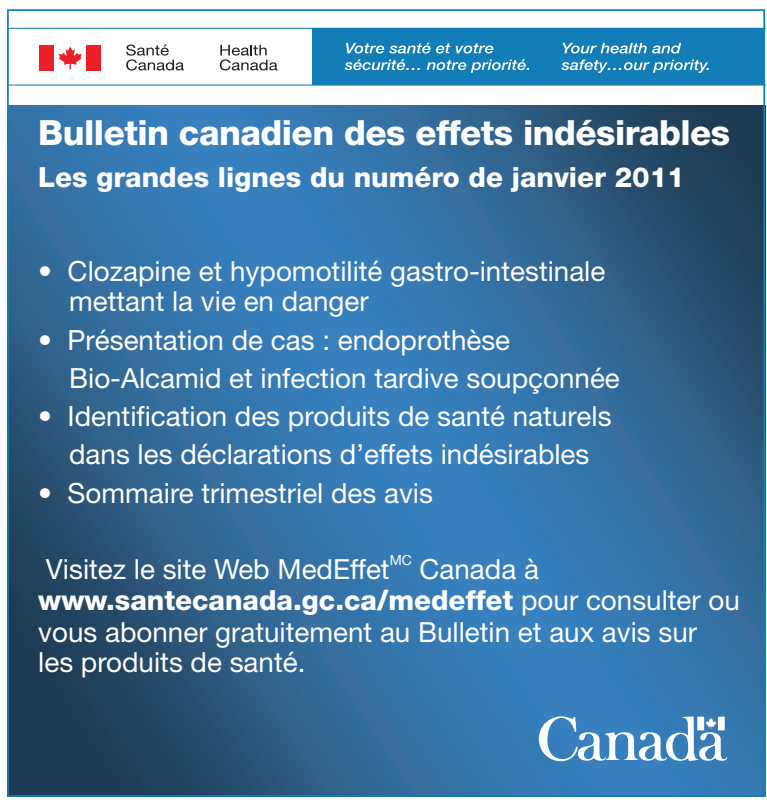

